STUDI

FRANCESI

\section{Studi Francesi}

Rivista quadrimestrale fondata da Franco Simone

165 (LV | III) | 2011

LA RAPPRESENTAZIONE DELLA MADRE NELLA

LETTERATURA FRANCESE DEL NOVECENTO a cura di Dario Cecchetti e Michele Mastroianni

\title{
Tony Johannot, Alfred de Musset et P.-J. Stahl, Voyage où il vous plaira
}

\author{
Lise Sabourin
}

\section{(2) OpenEdition \\ Journals}

\section{Édition électronique}

URL : http://journals.openedition.org/studifrancesi/5075

DOI : 10.4000/studifrancesi.5075

ISSN : 2421-5856

\section{Éditeur}

Rosenberg \& Sellier

Édition imprimée

Date de publication : 1 décembre 2011

Pagination : 662

ISSN : 0039-2944

Référence électronique

Lise Sabourin, «Tony Johannot, Alfred de Musset et P.-J. Stahl, Voyage où il vous plaira », Studi Francesi [En ligne], 165 (LV | III) | 2011, mis en ligne le 30 novembre 2015, consulté le 09 janvier 2021. URL :

http://journals.openedition.org/studifrancesi/5075; DOI : https://doi.org/10.4000/studifrancesi.5075

Ce document a été généré automatiquement le 9 janvier 2021.

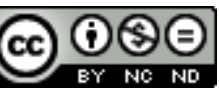

Studi Francesi è distribuita con Licenza Creative Commons Attribuzione - Non commerciale - Non opere derivate 4.0 Internazionale. 


\title{
Tony Johannot, Alfred de Musset et P.-J. Stahl, Voyage où il vous plaira
}

\author{
Lise Sabourin
}




\section{RÉFÉRENCE}

TONY JOHANNOT, ALFRED DE MUSSET et P.-J. STAHL, Voyage où il vous plaira, édition de Gilles CASTAGNÈs, Paris, Éditions Classiques Garnier, 2010, «Bibliothèque du xixe siècle», pp. 287.

1 Tout auréolé du succès de ses illustrations depuis sa rencontre avec Nodier en 1830, Tony Johannot a sans doute inspiré par la grâce de ses figures féminines la participation de Musset à ce Voyage où il vous plaira, publié en 1843 chez Hetzel, masqué comme auteur sous le pseudonyme de Stahl depuis les Scènes de la vie privée et publique des animaux, dont le principe de publication en feuilleton aux abonnés est repris. Né des dessins de Johannot, ce "cauchemar hilarant», à l'écriture mouvante au fil des livraisons, doit en effet sans doute un bon tiers de son texte, si ce n'est deux, à Hetzel, son coordonnateur.

2 Sur la base de l'autodafé de tous les récits d'aventures, ce Voyage s'amuse de l'itinéraire oriental devenu topique, dénonce l'illusion du pittoresque, affirme la parenté des mœurs prétendument différentes, s'insurge contre les descriptions tueuses d'imagination. Il propose de ce fait un véritable périple dans le récit de voyage littéraire depuis l'Antiquité comme chez les Européens romantiques, avec toute la scrutation que suppose l'élaboration de techniques narratives, mais en préservant la libre fantaisie d'un livre unique en son genre.

Gilles Castagnès, outre une préface nourrie (pp. 7-48), propose bien sûr chronologie et bibliographie, mais aussi un dossier (pp. 229-263) qui fournit en appendices des documents et manuscrits inédits ou non réédités: variantes du texte, articles consacrés à ce Voyage, à Tony Johannot ou à Hetzel-Stahl, confrontation sur la part prise par Musset selon son frère Paul et le portrait de Musset par Hetzel. 